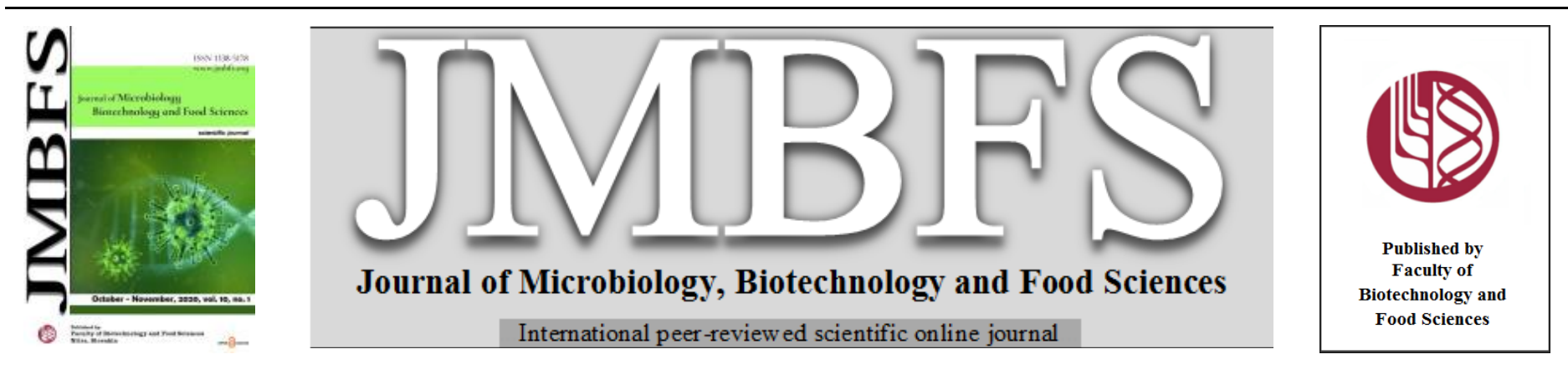

\title{
IN VITRO EFFECT OF RESORCINOL ON BOVINE SPERMATOZOA IN PROCESS OF CRYOPRESERVATION
}

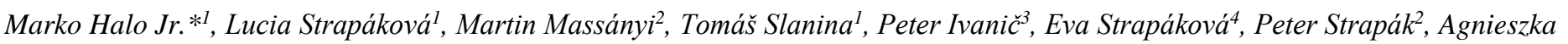 \\ Greñ $^{5}$, Marko Halo ${ }^{2}$, Peter Massányi ${ }^{1}$
}

Address(es): Ing. Marko Halo,

${ }^{1}$ Slovak University of Agriculture in Nitra, Faculty of Biotechnology and Food Sciences, Department of Animal Physiology, Tr. A. Hlinku 2, 949 76, Nitra, Slovak Republic.

${ }^{2}$ Slovak University of Agriculture in Nitra, Faculty of Agrobiology and Food Resources, Department of Animal Husbandry, Tr. A. Hlinku 2, 94976 Nitra, Slovak Republic.

${ }^{3}$ Slovak Biological Services, Kremnička 2, 97405 Banská Bystrica, Slovak Republic.

${ }^{4}$ Slovak University of Agriculture in Nitra, Faculty of Agrobiology and Food Resources, Department of Animal Genetics and Breeding Biology, Tr. A. Hlinku 2, 949

76, Nitra, Slovak Republic.

${ }_{5}^{5}$ Pedagogical University of Kraków, Faculty of Exact and Natural Sciences, Institute of Biology, ul. Podchorazych 2, 30-084 Cracow, Poland.

*Corresponding author: markohalo@yahoo.com

doi: 10.15414/jmbfs.2020.10.2.325-328

\section{ARTICLE INFO}

Received 29. 4. 2020

Revised 24. 9. 2020

Accepted 24. 9. 2020

Published 1. 10. 2020

Regular article OPEN $\partial_{\text {ACCESS }}$

\begin{abstract}
The purpose of present study was to observe the effect of resorcinol on bovine spermatozoa before and after cryopreservation. Fresh semen was obtained from six randomly chosen breeding bulls. Experimental samples were prepared by diluting the semen with six different concentrations of resorcinol (REZ1 - 4; REZ2 - 2; REZ3 - 1; REZ4 - 0.5; REZ5 - 0.25 and REZ6 - 0.152 mg.ml ${ }^{-1}$ ). Experimental groups were compared against control group (REZK). Using CASA method spermatozoa motility was evaluated before cryopreservation and also after thawing, during incubation at $37^{\circ} \mathrm{C}$ in time periods $0,5,10,15$ and 60 minutes. Negative effect of in vitro resorcinol addition was observed in all analysed parameters (MOT, PRO, VCL, ALH and BCF) in groups REZ1, REZ2 and REZ3. In contrast, positive impact mainly on motility and progressive motility was found in experimental groups with the lowest resorcinol concentration addition (REZ4, REZ5 and REZ6) in comparison to the control group. After thawing significant effect of resorcinol on motility parameters were observed within each experimental group. Group with the highest concentration of resorcinol (REZ1) had markedly negative impact on evaluated motility parameters. Results of our study clearly confirm toxic effect of resorcinol on motility parameters of spermatozoa, which depend on concentration and time period.
\end{abstract}

\section{INTRODUCTION}

Breeding of animals underwent significant changes in the past years. Insemination is a process which helped in genetic development of direct and indirect utility attributes and can be marked as one of classic biotechnologies. Nowadays, breeders cannot imagine reproduction without artificial insemination. Insemination is executed using fresh diluted semen or conserved semen. Conservation of semen can be done by chilling or freezing process (Diskin, 2018). Aim of cryopreservation is to maintain spermatozoa viability and functionality for decades at sub-zero temperature, despite harmful effects on cell structure (Grötter et al., 2019). During cryopreservation, cells are exposed to osmotic and thermic shocks that underway during dilution, cooling-freezing and thawing process. Mainly cellular membranes are affected during the freezingthawing process (Andrabi, 2009). Some individuals can have problem with cryotolerance and it only depends on a suitable freezing buffer (Šichtař et al., 2017). Several substances were exanimated, which can be a potential part of freezing extender (Akhter et al., 2012; Mousavi et al., 2019; Contreras et al., 2019).

Resorcinol (CAS no. 108-46-31; 1,3-benzenediol; $m$-hydroxybenzene; $m$ dihydroxyphenol) is widely used in the manufacture of tires and rubber goods. In a smaller quantities is added to pharmaceutical creams, used for the treatment of acne and to cosmetic products. Its occurrence has been recorded in canned molasses, roasted barley, cigarette smoke and coffee (Lych et al., 2002). Into medical use was resorcinol introduced in $19^{\text {th }}$ century (Welsh et al., 2008). Resorcinol was placed on a list of chemicals with potential of endocrine disruption by the European Union's Committee of Toxicity, Eco-toxicity and the Environment (CSTEE, 2003). Administration of orally taken resorcinol can be very hazardous on human health (Duran et al., 2004). Also it has been reported, that resorcinol can induce various toxic effect on central nervous system followed by myocardial depression, central necrosis of liver, tubular and glomerular degeneration of kidney (Thienes and Haley, 1972). EFSA established the lowest health-based limit for resorcinol on $0.12 \mathrm{mg} / \mathrm{kg}$ bodyweight (EFSA, 2010).

The objective of present in vitro study was to evaluate the effect of resorcinol on bull spermatozoa motility parameters before cryopreservation and following thawing.

\section{MATERIAL AND METHODS}

\section{Semen collection and processing}

Fresh semen was obtained from six randomly chosen breeding bulls using artificial vagina (Slovak Biological Services, a.s., Lužianky, Slovak Republic). Aliquots of ejaculates used as control groups (REZK) were diluted with physiological solution ( $\mathrm{NaCl} 0.9 \%$ Braun, B. Braun Melsungen AG, Germany) in ratio 1:40. Experimental samples were prepared according to the same dilution rate, using 6 different concentrations of resorcinol (Table 1), dissolved in the physiological solution. In advance were prepared resorcinol solutions to ensure the proper dissolution of resorcinol.

\section{Cryopreservation and motility analyses}

Amount of ejaculate, which was set by spectrophotometer was poured into a beaker in which was prepared $5 \mathrm{ml}$ of thinner. With the use of suction tubes, the straws were filled with ejaculate and subsequently inserted into freezing ramps. Ramps were afterwards inserted in refrigerator, where were kept for $4-6$ hours to undergo the equilibration process. After equilibration process straws were frozen in freezer by vapours of liquid nitrogen for the duration of 15 minutes. For 15 minutes glycerine based diluent was added and after diluting of the ejaculate, 
the activity of spermatozoa was checked. Ejaculate used to be frozen has to have activity of spermatozoa at the level of at least $60 \%$. Semen was inserted in liquid nitrogen in so called "baskets" for 7 minutes. After this time passed the "basket" with the straws inside liquid nitrogen where were stored for 5 minutes. After freezing straws were quickly moved into storage containers filled with liquid nitrogen which were transported to a laboratory after 24 hours. After pulling the samples out of a container, samples were defrosted for 30 seconds at the temperature of $37^{\circ} \mathrm{C}$ and the motility parameters were measured in time periods of $0,5,10,15$ and 60 minutes using CASA system (Gamčík et al., 1992).

Table 1 Concentration of resorcinol

\begin{tabular}{|c|c|c|c|}
\hline Group & $\begin{array}{l}\text { Volume of } \\
\text { ejaculate }(\mu \mathrm{l})\end{array}$ & Resorcinol (mg) & $\begin{array}{l}\text { Physiological } \\
\text { saline }(\mu \mathrm{l})\end{array}$ \\
\hline REZK & 20 & 0 & 800 \\
\hline REZ1 & 20 & 4 & 800 \\
\hline REZ2 & 20 & 2 & 800 \\
\hline REZ3 & 20 & 1 & 800 \\
\hline REZ4 & 20 & 0.5 & 800 \\
\hline REZ5 & 20 & 0.25 & 800 \\
\hline REZ6 & 20 & 0.152 & 800 \\
\hline
\end{tabular}

Semen was evaluated using the Computer assisted semen analysis (CASA) method with SpermVision software (Minitube, Tiefenbach, Germany) and the microscope Olympus BX 51 (Olympus, Japan). Each sample was placed into Makler counting chamber $(10 \mu \mathrm{m}$, Sefi-Medical Instruments, Germany) Following parameters in each sample were observed: MOT - motility of spermatozoa (\%); PRO - progressive motility percentage of spermatozoa (\%); VCL - velocity curved line $\left(\mu \mathrm{m} \cdot \mathrm{s}^{-1}\right) ; \mathrm{ALH}$ - amplitude of lateral head displacement $(\mu \mathrm{m})$ and $\mathrm{BCF}$ - beat cross frequency $(\mathrm{Hz})$ (Tirpák et al., 2019; Halo Jr. et al., 2019).

\section{Statistical analysis}

All data were analysed using the Statistical Analyses System (SAS 9.2. using of application Enterprise guide 5.1). Pearson's correlations between motility parameters of bovine spermatozoa before cryopreservation and after thawing in different time period were used. The level of significance was set at $* * *$ $(\mathrm{p}<0.001), * *(\mathrm{p}<0.01)$ and $*(\mathrm{p}<0.05)$ and results were interpreted as means and expressed with SD.

\section{RESULTS AND DISCUSSION}

\section{CASA analyses before cryopreservation}

Evaluation of motility parameters was realised before cryopreservation. Negative effect of in vitro resorcinol addition was observed in all analysed parameters (MOT, PRO, VCL, ALH and BCF) in groups REZ1, REZ2 and REZ3. But positive impact mainly on motility and progressive motility was recorded in experimental groups with the lowest concentrations of resorcinol addition (REZ4, REZ5 and REZ6) in comparison to the control group. (Table 2).

Table 2 Motility parameters of bovine spermatozoa before cryopreservation

\begin{tabular}{|c|c|c|c|}
\hline Group & Parameter & $\bar{x}$ & SD \\
\hline \multirow[t]{5}{*}{ REZK } & MOT (\%) & 87.20 & 4.13 \\
\hline & PRO (\%) & 83.79 & 4.27 \\
\hline & VCL $\left(\mu \mathrm{m} \cdot \mathrm{s}^{-1}\right)$ & 150.64 & 12.02 \\
\hline & ALH $(\mu \mathrm{m})$ & 4.25 & 0.29 \\
\hline & BCF (Hz) & 36.38 & 0.87 \\
\hline \multirow[t]{5}{*}{ REZ1 } & MOT (\%) & $23.71 *$ & 3.19 \\
\hline & PRO (\%) & $9.37 *$ & 5.70 \\
\hline & VCL $\left(\mu \mathrm{m} . \mathrm{s}^{-1}\right)$ & $82.29 *$ & 21.11 \\
\hline & ALH $(\mu \mathrm{m})$ & 3.82 & 0.53 \\
\hline & BCF (Hz) & $21.35^{*}$ & 2.14 \\
\hline \multirow[t]{5}{*}{ REZ2 } & MOT (\%) & $65.94 *$ & 14.56 \\
\hline & PRO (\%) & $53.25^{*}$ & 13.88 \\
\hline & $\operatorname{VCL}\left(\mu \mathrm{m} \cdot \mathrm{s}^{-1}\right)$ & 137.29 & 19.59 \\
\hline & ALH $(\mu \mathrm{m})$ & 4.14 & 0.50 \\
\hline & BCF (Hz) & $27.05^{*}$ & 1.32 \\
\hline \multirow[t]{5}{*}{ REZ3 } & MOT (\%) & $63.74 *$ & 10.85 \\
\hline & PRO (\%) & $50.58 *$ & 17.98 \\
\hline & $\operatorname{VCL}\left(\mu \mathrm{m} \cdot \mathrm{s}^{-1}\right)$ & 140.32 & 27.97 \\
\hline & ALH $(\mu \mathrm{m})$ & 3.99 & 0.71 \\
\hline & BCF (Hz) & $28.17 *$ & 4.24 \\
\hline \multirow[t]{5}{*}{ REZ4 } & MOT (\%) & 94.57 & 1.94 \\
\hline & PRO (\%) & 91.23 & 2.82 \\
\hline & $\operatorname{VCL}\left(\mu \mathrm{m} \cdot \mathrm{s}^{-1}\right)$ & 126.56 & 2.69 \\
\hline & ALH $(\mu \mathrm{m})$ & 4.66 & 0.18 \\
\hline & BCF (Hz) & $29.81 *$ & 1.06 \\
\hline
\end{tabular}

\begin{tabular}{|c|c|c|c|}
\hline \multirow[t]{5}{*}{ REZ5 } & MOT (\%) & 90.25 & 2.92 \\
\hline & PRO (\%) & 84.36 & 3.88 \\
\hline & VCL $\left(\mu \mathrm{m} \cdot \mathrm{s}^{-1}\right)$ & 135.29 & 5.41 \\
\hline & ALH $(\mu \mathrm{m})$ & 4.50 & 0.31 \\
\hline & BCF (Hz) & 32.34 & 1.71 \\
\hline \multirow[t]{5}{*}{ REZ6 } & MOT (\%) & $95.15^{*}$ & 1.54 \\
\hline & PRO (\%) & 91.14 & 2.43 \\
\hline & $\operatorname{VCL}\left(\mu \mathrm{m} \cdot \mathrm{s}^{-1}\right)$ & 121.75 & 3.70 \\
\hline & ALH $(\mu \mathrm{m})$ & 5.17 & 0.30 \\
\hline & BCF (Hz) & $28.39^{*}$ & 2.33 \\
\hline
\end{tabular}

Spermatozoa motility

Motility of spermatozoa before cryopreservation was $87.20 \pm 4.13 \%$ in contro group (REZK), after thawing motility decreased to $47.18 \pm 11.27 \%$. After thawing (Time 0) spermatozoa motility showed decreased value for all doses of resorcinol in comparison to the control group. After 5 and 10 minutes of the culture significant differences were found (groups REZ1, REZ2, REZ3), and all values in experimental groups were lower compared to control. Only in the group REZ4 value of motility was slightly higher compared to control group after 15 minutes of in vitro cultivation with lower values in other experimental groups. Similar tendency as at Times $0,5,10$ was found at Time 60 (Figure 1).

\section{MOT}

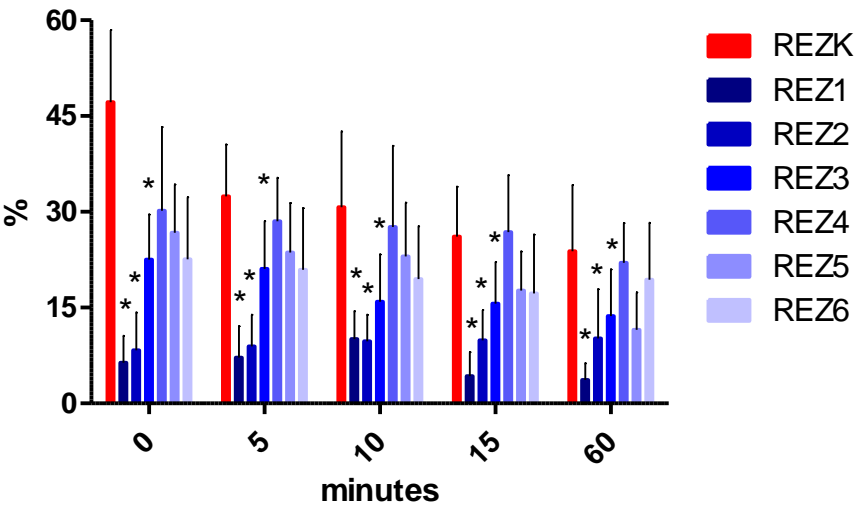

Figure 1 The effect of resorcinol on the total motility (\%). (REZK - 0; REZ1- 4; REZ2 - 2; REZ3 - 1; REZ4 - 0.5; REZ5 - 0.25; REZ6 - 0.152 mg.ml ${ }^{-1}$ of resorcinol). Each bar represents the mean $( \pm \mathrm{SD})$. The level of significance was set at $* * *(\mathrm{p}<0.001), * *(\mathrm{p}<0.01)$ and $*(\mathrm{p}<0.05)$

\section{Progressive spermatozoa motility}

Markedly negative effect on spermatozoa progressive motility was found in experimental group with the highest dose of resorcinol (REZ1) during whole cultivation. At Times 0 and 60 the average progressive spermatozoa motility was decreased in all experimental groups compared to the controls $(34.73 \pm 14.64 \%$; $23.37 \pm 7.69 \%$ ). After 10 and 15 minutes of cultivation slightly increased values in group REZ4 were detected compared to control. After 60 minutes of culture the progressive spermatozoa motility was in the control group (REZK) $12.63 \pm$ $8.64 \%$ and no significant differences were found in experimental groups with lower concentration (Figure 2). On the other hand, significant decrease $(p<0.05)$ was detected in groups with higher resorcinol concentration (REZ1, REZ2, REZ3).

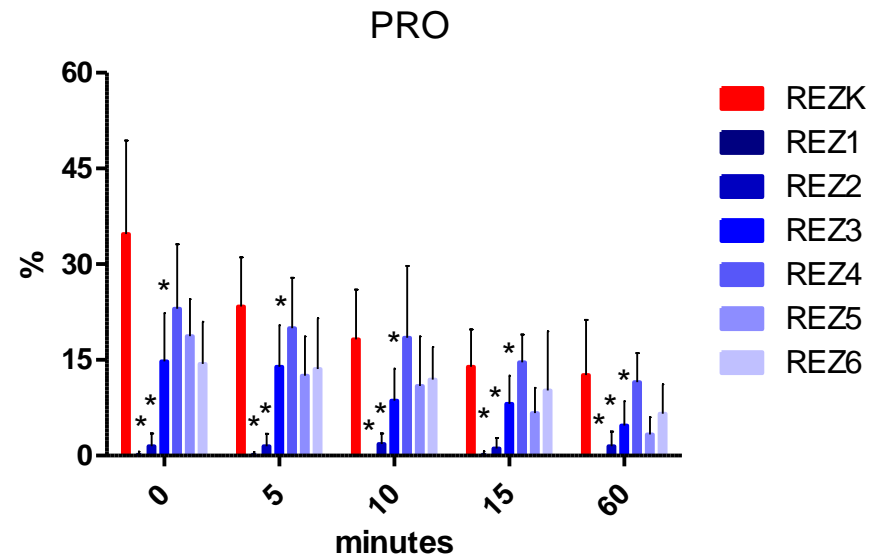

Figure 2 The effect of resorcinol on the progressive motility (\%). (REZK - 0; REZ1- 4; REZ2 - 2; REZ3 - 1; REZ4 - 0.5; REZ5 - 0.25; REZ6 - 0.152 mg.ml ${ }^{-1}$ 
of resorcinol). Each bar represents the mean $( \pm \mathrm{SD})$. The level of significance was set at $* * *(\mathrm{p}<0.001), * *(\mathrm{p}<0.01)$ and $*(\mathrm{p}<0.05)$

\section{Velocity parameter}

After thawing (Time 0) spermatozoa velocity curved line was the highest in the group REZ6 $\left(121.72 \pm 28.91 \mu \mathrm{m}_{\mathrm{s}} \mathrm{s}^{-1}\right)$ compared to control group REZK $\left(111.95 \pm 18.67 \mu \mathrm{m} . \mathrm{s}^{-1}\right)$, other experimental groups had lower values of velocity curved line compared to control. Similar trend was observed after 5 minutes of cultivation. At Time 10, 15 and 60 minutes spermatozoa velocity curved line in all doses of resorcinol was decreased in comparison to control group with significant difference in groups with higher resorcinol (REZ1-3) concentration (Figure 3).

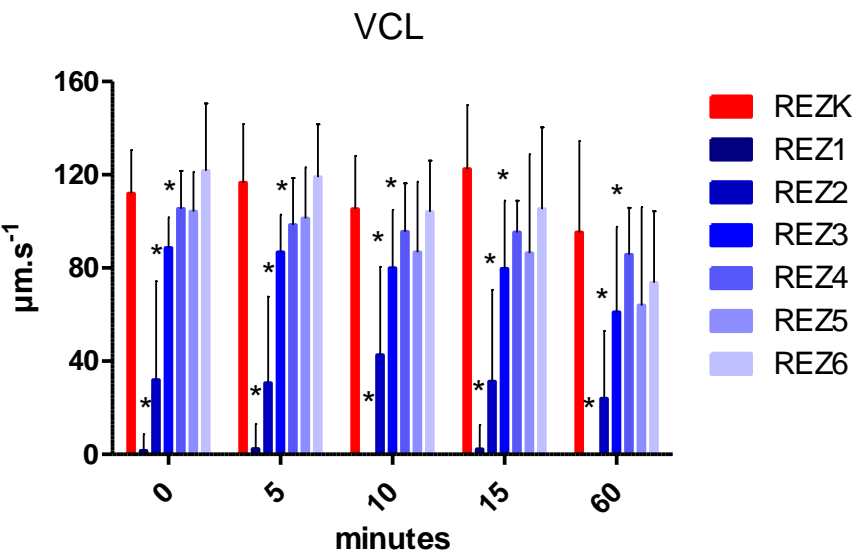

Figure 3 The effect of resorcinol on the velocity curved line $\left(\mu \mathrm{m} \cdot \mathrm{s}^{-1}\right)$. (REZK -0 REZ1 - 4; REZ2 - 2; REZ3 - 1; REZ4 - 0.5; REZ5 - 0.25; REZ6 - 0.152 mg.ml ${ }^{1}$ of resorcinol). Each bar represents the mean $( \pm \mathrm{SD})$. The level of significance was set at $* * *(\mathrm{p}<0.001), * *(\mathrm{p}<0.01)$ and $*(\mathrm{p}<0.05)$.

\section{Other fine motility parameters}

At Time 0 amplitude of lateral head displacement in groups REZ5 and REZ6 had increased values compared to control group. This trend was also recorded after 5 minutes of cultivation, but only in the experimental group with the lowest dose of resorcinol (REZ6). After 10, 15 and 60 minutes of cultivation a negative effect of resorcinol on spermatozoa was found. Values of amplitude of lateral head displacement showed no significant differences in groups REZ6, REZ5 and REZ4 (Figure 4).

\section{$\mathrm{ALH}$}

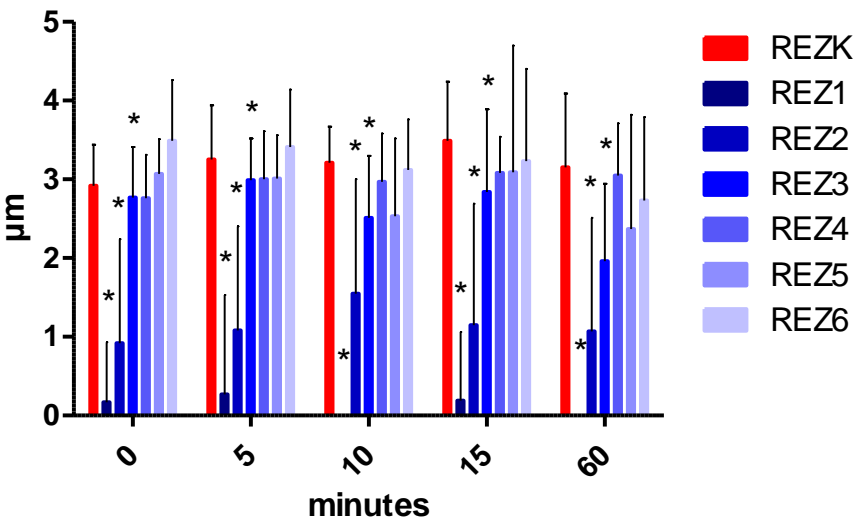

Figure 4 The effect of resorcinol on the amplitude of lateral head displacement ( $\mu \mathrm{m})$. $($ REZK - 0; REZ1- 4; REZ2 - 2; REZ3 - 1; REZ4 - 0.5; REZ5 - 0.25; REZ6 $-0.152 \mathrm{mg}^{-1} \mathrm{ml}^{-1}$ of resorcinol). Each bar represents the mean $( \pm \mathrm{SD})$. The level of significance was set at $* * *(p<0.001), * *(p<0.01)$ and $*(p<0.05)$.

Beat cross frequency (BCF) in control group REZK were between $35.8 \mathrm{~Hz}$ (Time 0 ) and $22.56 \mathrm{~Hz}$ (after 60 minutes after thawing). Negative effect of the highest dose of resorcinol (REZ1) was also found on beat cross frequency. This trend was with significant differences is the same groups as for ALH - REZ1 and REZ2 (Figure 5).

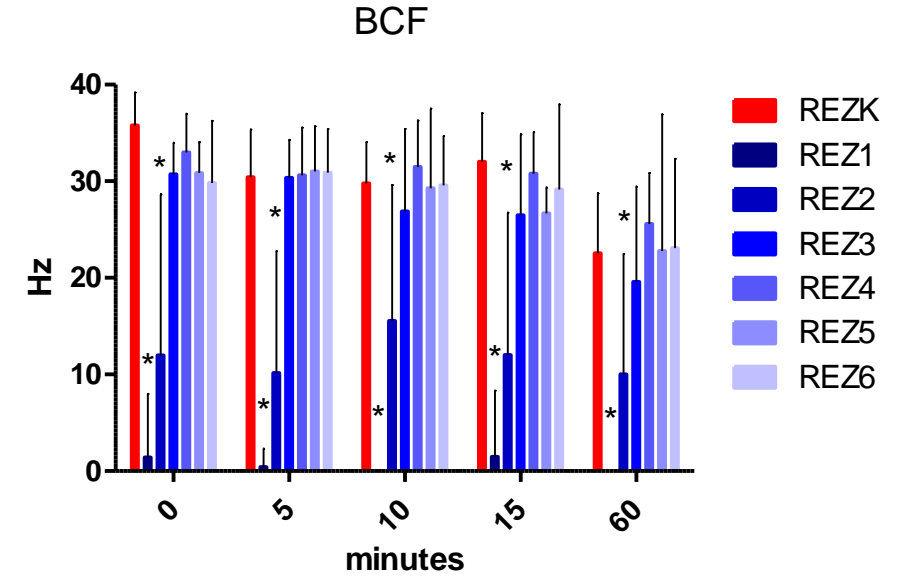

Figure 5 The effect of resorcinol on the beat cross frequency $(\mathrm{Hz})$. (REZK -0 REZ1- 4; REZ2 - 2; REZ3 - 1; REZ4 - 0.5; REZ5 - 0.25; REZ6 - 0.152 mg.ml-1 of resorcinol). Each bar represents the mean $( \pm \mathrm{SD})$. The level of significance was set at $* * *(\mathrm{p}<0.001), * *(\mathrm{p}<0.01)$ and $*(\mathrm{p}<0.05)$.

Significant $* \mathrm{p}<0.05$ decrease of values was observed after thawing of samples and following cultivation (Time $0,5,10,15$ and 60 minutes) in monitored parameters (MOT, PRO, VCL, ALH and BCF) (Table 3).

Table 3 Differences between motility parameters of bovine spermatozoa before cryopreservation and after thawing in different time period

\begin{tabular}{|c|c|c|c|c|c|c|}
\hline \multirow[t]{2}{*}{ Group } & \multirow[t]{2}{*}{ Parameter } & \multicolumn{5}{|l|}{ Time } \\
\hline & & $\mathbf{0}$ & 5 & 10 & 15 & 60 \\
\hline \multirow[t]{5}{*}{ REZK } & MOT (\%) & $40.02 *$ & $54.76^{*}$ & $56.48^{*}$ & $61.05 *$ & $63.36^{*}$ \\
\hline & PRO (\%) & 49.07* & $60.43^{*}$ & $65.55^{*}$ & $69.85^{*}$ & $71.17 *$ \\
\hline & $\begin{array}{l}\text { VCL } \\
\left(\mu \mathrm{m} \cdot \mathrm{s}^{-1}\right)\end{array}$ & 38.70 & 34.07 & $45.40^{*}$ & 28.16 & $55.43^{*}$ \\
\hline & ALH $(\mu \mathrm{m})$ & $1.34 *$ & $1.01 *$ & $1.04 *$ & 0.77 & $1.11^{*}$ \\
\hline & BCF (Hz) & 0.59 & 5.97 & 6.59 & 4.37 & $13.82^{*}$ \\
\hline \multirow[t]{5}{*}{ REZ1 } & MOT (\%) & $17.32 *$ & $16.56^{*}$ & $13.65^{*}$ & $19.45^{*}$ & $20.03 *$ \\
\hline & PRO (\%) & $9.27 *$ & $9.27 *$ & $9.37 *$ & $9.26 *$ & $9.37 *$ \\
\hline & $\begin{array}{l}\text { VCL } \\
\left(\mu \mathrm{m} . \mathrm{s}^{-1}\right)\end{array}$ & $80.76^{*}$ & 79.97* & $82.30 *$ & $80.03 *$ & $82.30 *$ \\
\hline & ALH $(\mu \mathrm{m})$ & $3.66^{*}$ & $3.55^{*}$ & $3.83 *$ & $3.64 *$ & $3.83^{*}$ \\
\hline & BCF (Hz) & 19.93* & 20.94* & $21.36^{*}$ & $19.87 *$ & $21.36^{*}$ \\
\hline \multirow[t]{5}{*}{ REZ2 } & MOT (\%) & $57.62 *$ & $57.03 *$ & $56.22 *$ & $56.06 *$ & $55.77^{*}$ \\
\hline & PRO (\%) & $51.80 *$ & $51.79 *$ & $51.44^{*}$ & $52.12 *$ & $51.78^{*}$ \\
\hline & $\begin{array}{l}\text { VCL } \\
\left(\mu \mathrm{m} . \mathrm{s}^{-1}\right)\end{array}$ & $105.42 *$ & $106.66^{*}$ & $94.66^{*}$ & $106.01 *$ & $113.38^{*}$ \\
\hline & ALH $(\mu \mathrm{m})$ & $3.22 *$ & $3.06^{*}$ & $2.59 *$ & $2.3^{*}$ & $3.07 *$ \\
\hline & BCF (Hz) & 15.08 & 16.91 & 11.50 & 15.05 & 17.05 \\
\hline \multirow[t]{5}{*}{ REZ3 } & MOT (\%) & $41.24 *$ & $42.04 *$ & $47.83^{*}$ & $48.11 *$ & $50.07 *$ \\
\hline & PRO (\%) & $35.81 *$ & $36.67 *$ & $41.93^{*}$ & $42.43 *$ & $45.86^{*}$ \\
\hline & $\begin{array}{l}\text { VCL } \\
\left(\mu \mathrm{m} . \mathrm{s}^{-1}\right)\end{array}$ & $51.69 *$ & $53.65^{*}$ & $60.34 *$ & $60.69 *$ & $79.37 *$ \\
\hline & $\mathbf{A L H}(\boldsymbol{\mu m})$ & 1.22 & 0.99 & $1.48 *$ & 1.15 & $1.77^{*}$ \\
\hline & BCF (Hz) & -2.557 & -2.16 & 1.30 & 1.69 & 8.59 \\
\hline \multirow[t]{5}{*}{ REZ4 } & MOT (\%) & $64.39 *$ & $66.4^{*}$ & $66.96^{*}$ & $67.75^{*}$ & $72.56^{*}$ \\
\hline & PRO (\%) & $68.19^{*}$ & $71.26^{*}$ & $72.75^{*}$ & $76.63 *$ & $79.71 *$ \\
\hline & $\begin{array}{l}\text { VCL } \\
\left(\mu \mathrm{m} \cdot \mathrm{s}^{-1}\right)\end{array}$ & 21.11 & $28.09 *$ & $31.05^{*}$ & $31.25^{*}$ & $40.92 *$ \\
\hline & $\mathbf{A L H}(\boldsymbol{\mu m})$ & $1.90^{*}$ & $1.67 *$ & $1.69 *$ & $1.58^{*}$ & $1.61 *$ \\
\hline & BCF (Hz) & -3.17 & -1.81 & -1.67 & -0.98 & 4.25 \\
\hline \multirow[t]{5}{*}{ REZ5 } & MOT (\%) & $63.55^{*}$ & $66.61 *$ & $67.24 *$ & $72.57 *$ & $78.72 *$ \\
\hline & PRO (\%) & $65.66^{*}$ & $71.83^{*}$ & $73.41^{*}$ & $77.70 *$ & $81.01 *$ \\
\hline & $\begin{array}{l}\text { VCL } \\
\left(\mu \mathrm{m} . \mathrm{s}^{-1}\right)\end{array}$ & 31.10 & 34.02 & $48.59 *$ & $48.99 *$ & $71.34 *$ \\
\hline & ALH $(\mu \mathrm{m})$ & 1.43 & 1.49 & $1.97 *$ & 1.41 & $2.13^{*}$ \\
\hline & BCF (Hz) & 1.49 & 1.34 & 3.07 & 5.68 & 9.57 \\
\hline \multirow[t]{5}{*}{ REZ6 } & MOT (\%) & $72.60 *$ & $74.23 *$ & $75.67 *$ & $77.92 *$ & $75.79 *$ \\
\hline & PRO (\%) & $76.78^{*}$ & $77.57 *$ & $79.21 *$ & $80.91 *$ & $84.58^{*}$ \\
\hline & $\begin{array}{l}\text { VCL } \\
\left(\mu \mathrm{m} \cdot \mathrm{s}^{-1}\right)\end{array}$ & 0.03 & 2.70 & 17.72 & 16.42 & 48.11 \\
\hline & ALH $(\mu \mathrm{m})$ & $1.68 *$ & $1.77 *$ & $1.94 *$ & $2.05^{*}$ & $2.45^{*}$ \\
\hline & BCF (Hz) & -1.43 & -2.49 & -1.18 & -0.74 & 5.33 \\
\hline
\end{tabular}

Legend: (REZK - 0; REZ1-4; REZ2 - 2; REZ3 - 1; REZ4 - 0.5; REZ5 - 0.25; REZ6 $-0.152 \mathrm{mg} \cdot \mathrm{ml}^{-1}$ of resorcinol). The level of significance was set at $* * *$ $(\mathrm{p}<0.001), * *(\mathrm{p}<0.01)$ and $*(\mathrm{p}<0.05)$ 
CASA method (Computer assisted semen analyses) is often used for evaluation of motility parameters (Massányi et al., 2002; 2008; 2011). Analysing of spermatozoa motility is important factor for successful insemination but also for experimental studies (Palacín et al., 2013; Tvrdá et al., 2013).

Rafajová (2011) in her study observed effect of resorcinol on bovine spermatozoa parameters. Spermatozoa motility after in vitro addition of resorcinol in amount of $2 \mathrm{mg} \cdot \mathrm{ml}^{-1}$ was $78.95 \pm 6.80 \%$ and in amount of $1 \mathrm{mg} \cdot \mathrm{ml}^{-1}$ $80.47 \pm 8.99 \%$ in Time 0 whereas in our study values of motility was $65.94 \pm 14.56 \%$ and $63.74 \pm 10.85 \%$. Welsch et al., (2008) studied two-generation toxicity of resorcinol administered via drinking water to $\mathrm{Ctrl}: \mathrm{CD}(\mathrm{SD})$ rats. Rats were exposed of 4 different concentration of resorcinol $(120,360,1000$ and 3000 $\left.\mathrm{mg} \cdot \mathrm{ml}^{-1}\right)$. After administration of $3000 \mathrm{mg}^{-1} \mathrm{l}^{-1}$ of resorcinol had no-observedadverse-effect, while the $1000 \mathrm{mg} \cdot \mathrm{l}^{-1}$ dose had the no-observed-effect level. None of the reproductive end points observed during two generations were no negatively affected by high resorcinol doses served via drinking water Cytotoxicity of resorcinol was tested on 3T3 fibroblast for short (3 hours) and long term (72 hours or 6 weeks). Resorcinol in doses of $2500-4000 \mu \mathrm{g} . \mathrm{cm}^{-3}$ caused mitochondrial activity inhibition (Skowroń and Zapór, 2004). Study of Burnett et al., (1976) on pregnant Charles River CD rats focused on effect of topical application of hair preparation containing resorcinol did not show negative developmental effects. In following study of Burnett and Goldenthal (1988), where was evaluated effect of topical application of hair-colouring formulations containing resorcinol on Sprague-Dawley rats. There was no adverse effect on fertility observed.

As Lynch et al., (2002) states in his results, no occur of thyroid hormone synthesis after resorcinol administration to rats. In a two year bioassay these effects were not found after doses up to $520 \mathrm{mg} / \mathrm{kg} / \mathrm{day}$ on rats.

Muiño et al., (2008) recorded, that total motility in fresh ejaculate of Holstein bulls was $82.3 \pm 9.8 \%$ and after cryopreservation decreased at Time 0 to $75.8 \pm 12.8 \%$, after 2 hours to $69.8 \pm 16.3 \%$ and after 4 hours to $59.4 \pm 20.9 \%$, what confirms decreasing trend of motility after thawing in the control from $87.2 \pm 4.13 \%$ to $47.18 \pm 11.27 \%$ in our study.

\section{CONCLUSION}

Results from this in vitro study confirm, that resorcinol has dose- and timedependent effect on the spermatozoa. Interestingly, low concentration of resorcinol do not negative effect spermatozoa motility spermatozoa and/or have even positive effect. But it has to be stated that higher concentrations are toxic, resulting in significant decrease of motility parameters.

Acknowledgments: This work was supported by projects VEGA 1/0539/18, VEGA 1/0392/20, APVV-16-0289 and KEGA 010/SPU-4/2018.

\section{REFERENCES}

Akhter, S., Ansari, M. S., Andrabi, S. M. H., Rakha, B. A., Ullah, N., \& Khalid, M. (2012). Soya-lecithin in extender improves the freezability and fertility of buffalo (Bubalus bubalis) bull spermatozoa. Reproduction in Domestic Animals, 47(5), 815-819. https://doi.org/10.1111/j.1439-0531.2011.01973.x

Andrabi, S. M. H. (2009). Factors affecting the quality of cryopreserved buffalo (Bubalus bubalis) bull spermatozoa. Reproduction in Domestic Animals, 44(3), 552-569. https://doi.org/10.1111/j.1439-0531.2008.01240.x

Burnett, C., Goldenthal, E. I., Harris, S. B., Wazeter, F. X., Strausburg, J., Kapp R., \& Voelker, R. (1976). Teratology and percutaneous toxicity studies on hair dyes. Journal of Toxicology and Environmental Health, Part A Current Issues, 1(6), 1027-1040. https://doi.org/10.1080/15287397609529406

Burnett, C. M., \& Goldenthal, E. I. (1988). Multigeneration reproduction and carcinogenicity studies in Sprague-Dawley rats exposed topically to oxidative hair-colouring formulations containing p-phenylenediamine and other aromatic amines. Food and Chemical Toxicology, 26(5), 467-474. https://doi.org/10.1016/0278-6915(88)90059-2

Contreras, M. J., Treulen, F., Arias, M. E., Silva, M., Fuentes, F., Cabrera, P., \& Felmer, R. (2019). Cryopreservation of stallion semen: Effect of adding antioxidants to the freezing medium on sperm physiology. Reproduction in Domestic Animals. https://doi.org/10.1111/rda.13611

CSTEE. (2003). Opinion of the scientific committee on toxicity, ecotoxicity andthe environment (CSTEE) on "Two study reports on endocrine disrupters byWRc-NSF and BKH Consulting Engineers." European Commission, CSTEE $40^{\text {th }}$ Plenary Meeting, 12-13 November.

Diskin, M.G. (2018). Semen handling, time of insemination and insemination technique in cattle. Animal, 12(s1), 75-84. https://doi.org/10.1017/S1751731118000952

Duran, B., Gursoy, S., Cetin, M., Demirkoprulu, N., Demirel, Y., \& Gurelik, B. (2004). The oral toxicity of resorcinol during pregnancy: a case report. Journal of Toxicology: Clinical Toxicology, 42(5), 663-666. https://doi.org/10.1081/CLT200026966

EFSA. (2010) EFSA panel on food additives and nutrient sources added to food (ANS); Scientific Opinion on the use of Resorcinol as a food additive. EFSA Journal, 8(1), 1411. https://doi.org/10.2903/j.efsa.2010.1411
Gamčík, P., Kozumplík, J., Mesároš, P., Schvarc, F., Vlček, Z., Zibrín, M. (1992). Andrology and artificial insemination of farm animals Bratislava: Príroda, s. 299. ISBN 80-07-00540-4.

Grötter, L.G., Cattaneo, L., Marini, P.E., Kjelland, M.E., \& Ferré, L.B. (2019). Recent advances in bovine sperm cryopreservation techniques with a focus on sperm post-thaw quality optimization. Reproduction in Domestic Animals, 54(4), 655-665. https://doi.org/10.1111/rda.13409

Halo Jr, M., Massányi, P., Greń, A., Lasak, A., Slanina, T., Ondruška, L., Muchacka, R., Galbavy, D., Ivanic, P., Schneir, E.R. \& Formicki, G. (2019) Time and dose-dependent effects of viscum album quercus on rabbit spermatozoa motility and viability in vitro. Physiological Research, 68(6), 955-972. https://doi.org/10.33549/physiolres.934223

Lynch, B.S., Delzell, E.S., \& Bechtel, D.H. (2002). Toxicology review and risk assessment of resorcinol: thyroid effects. Regulatory Toxicology and Pharmacology, 36(2), 198-210. https://doi.org/10.1006/rtph.2002.1585

Massányi, P., Trandžík, J., Lukáč, N., Toman, R., Halo, M., \& Strapák, P. (2002). Evatuation of spermatozoa motility using computed technique (in Slovak). Nitra: Slovak University of Agriculture, $81 \mathrm{pp}$.

Massányi, P., Chrenek, P., Lukáč, N., Makarevich, A. V., Ostró, A., Živčák, J. \& Bulla, J. (2008). Comparison of different evaluation chambers for analysis of rabbit spermatozoa motility parameters using CASA system. Slovak Journal of Animal Science, 41(2), 60-66.

Massányi, P., Tvrdá, E., Rafajová, M. \& Lukáč, N. (2011). The effect of trehalose, caffeine and glutathione on bovine spermatozoa: 1. Motility in vitro Contemporary Agriculture - The Serbian Journal of Agricultural Sciences Savremena Poljoprivreda, 60 (3-4), 387-397.

Mousavi, S. M., Towhidi, A., Zhandi, M., Amoabediny, G., MohammadiSangcheshmeh, A., Sharafi, M., \& Hussaini, S. M. H. (2019). Comparison of two different antioxidants in a nano lecithin-based extender for bull sperm cryopreservation. Animal reproduction science, 209, 106171. https://doi.org/10.1016/j.anireprosci.2019.106171

Muiño, R., Tamargo, C., Hidalgo, C. O., \& Peña, A.I. (2008). Identification of sperm subpopulations with defined motility characteristics in ejaculates from Holstein bulls: effects of cryopreservation and between-bull variation. Animal reproduction science, $109(1-4), \quad 27-39$. https://doi.org/10.1016/j.anireprosci.2007.10.007

Palacín, I., Vicente-Fiel, S., Santolaria, P., \& Yániz, J. L. (2013). Standardization of CASA sperm motility assessment in the ram. Small ruminant research, 112(13), 128-135. https://doi.org/10.1016/j.smallrumres.2012.12.014

Rafajová, M. (2011). Quantification of the motility and structure of bovine spermatozoa after an addition of selected implementors in vitro: Dissertation thesis. Nitra : SUA, $177 \mathrm{pp}$.

Skowroń, J., \& Zapór, L. (2004). Cytotoxicity of resorcinol under short-and longterm exposure in vitro. International Journal of Occupational Safety and Ergonomics, 10(2), 147-156. https://doi.org/10.1080/10803548.2004.11076603 Šichtař, J., Nehasilová, A., Šimoník, O., \& Bubeníčková, F. (2017). Effect of two freezing extenders on characteristic of fresh and frozen-thawed semen in endangered Old Kladruber stallions-A pilot study. Czech Journal of Animal Science, 62(6), 227-233. https://doi.org/10.17221/76/2016-cjas

Thienes, C. H., \& Haley, T. J. (1972). Miscellaneous depressant vapors. Clinical Toxicology, 57.

Tirpák, F., Slanina, T., Tomka, M., Židek, R., Halo Jr, M., Ivanič, P., ... \& Massányi, P. (2019). Exposure to non-ionizing electromagnetic radiation of public risk prevention instruments threatens the quality of spermatozoids. Reproduction in Domestic Animals, 54(2), 150-159. https://doi.org/10.1111/rda.13338

Tvrdá, E., Kňažická, Z., Lukáčová, J., Schneidgenová, M., Goc, Z., Greń, A., ... \& Lukáč, N. (2013). The impact of lead and cadmium on selected motility, prooxidant and antioxidant parameters of bovine seminal plasma and spermatozoa. Journal of Environmental Science and Health Part AToxic/Hazardous Substances \& Environmental Engineering, 48(10), 1292-1300. Welsch, F., Nemec, M. D., \& Lawrence, W. B. (2008). Two-generation reproductive toxicity study of resorcinol administered via drinking water to $\mathrm{Crl}$ : CD (SD) rats. International journal of toxicology, 27(1), 43-57. https://doi.org/10.1080/10915810701876679 